\title{
ETIOLOGIA DAS INFECÇÕES INTRAMAMÁRIAS EM VACAS PRIMÍPARAS AO LONGO DOS PRIMEIROS QUATRO MESES DE LACTAÇÃO
}

\author{
AETIOLOGY OF MAMMARY INFECTIONS IN PRIMIPAROUS COWS DURING \\ THE FIRST FOUR MONTHS OF LACTATION
}

\author{
Alessandra Laffranchi ${ }^{1}$ Ernst Eckehardt Müller ${ }^{2}$ Julio Cesar de Freitas ${ }^{2}$ \\ Lucienne Garcia Pretto-Giordano ${ }^{3}$ Juliana Alves Dias ${ }^{4}$ Rogério Salvador $^{4}$
}

RESUMO

De 88 vacas primíparas, oriundas de quatro rebanhos leiteiros, foram colhidas 1985 amostras de leite, ao longo dos 120 dias pós-parto, das quais 457 (23,02\%) apresentaram resultados microbiológicos positivos. Os estafilococos coagulase negativos (ECN) foram isolados em 316 $(69,14 \%)$ amostras, Corynebacterium bovis em 56 (12,25\%), estreptococos em 41 (8,97\%) e estafilococos coagulase positivos (ECP) em 38 (8,31\%). Mastite clínica foi detectada em nove $(10,23 \%)$ vacas. No primeiro dia pós-parto, 57 (64,77\%) animais e $114(32,66 \%)$ quartos apresentaram exames bacteriológicos positivos. Até o décimo quarto dia, ocorreu um decréscimo acentuado no número de vacas e quartos infectados, que posteriormente tendeu a estabilizar. Os ECN foram as bactérias mais isoladas ao longo de todo experimento, enquanto o número de estreptococos decresceu acentuadamente nas duas primeiras semanas pós-parto. As infecções por $\boldsymbol{C}$. bovis aumentaram progressivamente a partir do parto. Entre os ECN, predominaram o S. hyicus e o S. intermedius e, nos estreptococos, os do grupo C e D. A contagem média de células somáticas (CCS), nos quartos infectados, foi de 508,914/m ,

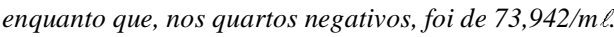

Palavras-chave: mastite, etiologia, vacas primíparas.

SUMMARY

From 88 primiparous cows, belonging to four dairy herds, during 120 days after parturition, one thousand and eighty five milk samples collected, showed 457 (23.02\%) positive microbiological results. Coagulase negative staphylococci (CNS) were isolated in $316(69.14 \%)$ samples, Corynebacterium bovis in $56(12.25 \%)$, streptococci in $41(8.97 \%)$ and coagulase positive staphylococci (CPS) in $38(8.31 \%)$. Clinical mastitis was detected in $9(10.23 \%)$ cows. In the first day after parturition, 57 (64.77\%) animals and $114(32.66 \%)$ quarters were bacteriologically positive. Until the $14^{\text {th }}$ day there was a remarkable decrease in the number of infections in cows and in quarters, numbers which tended to stabilize later. CNS were isolated through all the experiment while the streptococci tended to disappear in the first few weeks. The infections by $\mathrm{C}$. bovis steadily increased after parturition. Of CNS, S. hyicus and $\mathrm{S}$. intermedius were predominant, and in the streptococci the $C$ and $D$ groups. The average somatic cell count (SCC) was 508.914/m $\ell$ in the infected ones and in the negative quarters It was $73.942 / \mathrm{m} \ell$.

Key words: mastitis, aetiology, primiparous cows.

\section{INTRODUÇÃO}

Dentre as diferentes doenças microbianas, a mastite bovina é a de maior impacto econômico na pecuária leiteira pelos prejuízos que causa ao produtor e à indústria de produtos lácteos. Produtores e técnicos, normalmente, adotam medidas preventivas para as vacas em lactação, considerando os animais jovens refratários à infecção (HALLBERG et al., 1995). Os primeiros relatos de mastite em vacas primíparas datam das décadas de vinte e trinta (STABELFORTH et $\boldsymbol{a l}$., 1935), mas somente os trabalhos realizados a partir dos anos 70 demonstraram a sua importância, principalmente no que se refere à diminuição na

\footnotetext{
${ }^{1}$ Médico Veterinário, aluno do Programa de Mestrado em Sanidade Animal, Departamento de Medicina Veterinária Preventiva (DMVP), Centro de Ciências Agrárias (CCA), Universidade Estadual de Londrina (UEL).

${ }^{2}$ Professores, (Laboratório de Microbiologia, Veterinária e Doenças Infecciosas), DMVP/CCA/UEL, 86051-990, Londrina, Pr. Autor para correspondência.

${ }^{3}$ Médico Veterinário, Mestre, Laboratório de Microbiologia Veterinária e Doenças Infecciosas, DMVP/UEL.

${ }^{4}$ Aluno do Curso de Graduação de Medicina Veterinária, UEL, E-mail: muller@uel.br.
} Recebido para publicação em 11.02.00. Aprovado em 04.04.01 
produção de leite (MUNCH-PETERSEN, 1970; OLIVER \& MITCHELL, 1983; FOX et al., 1995).

As infecções da glândula mamária, em novilhas, podem prejudicar o desenvolvimento do tecido glandular, afetando adversamente a diferenciação das células secretoras (TRINIDAD $\boldsymbol{e t}$ al., 1990). Em cortes histológicos, HALLBERG $\boldsymbol{e t}$ al. (1995) demonstraram menor área de epitélio alveolar, aumento de estroma e infiltração de leucócitos, o que acarreta diminuição na secreção láctea.

No Brasil, os primeiros trabalhos que relatam a ocorrência de infecções intramamárias em novilhas e vacas primíparas foram realizados nos Estados de São Paulo e Paraná (COSTA et al.,1996, 1999; PARDO et al., 1998). Essas pesquisas demonstraram infecções em $26,5 \%$ a $47,6 \%$ dos quartos examinados, nas duas primeiras semanas pós-parto, com predominância dos estafilococos coagulase negativos (ECN).

A ocorrência de ECN, em novilhas, no pré e pós-parto, está em parte correlacionada à presença deles na microbiota normal da pele e mucosa, assim como na colonizaçã do esfíncter e canal do teto dos bovinos (TRINIDAD et al., 1990). Parte dos animais livra-se da infecção nas primeiras semanas pós-parto em conseqüência dos procedimentos de ordenha, mas um número elevado de vacas primíparas permanece infectado por longos períodos (DANIEL et al., 1986; MATTHEWS $\boldsymbol{e} \boldsymbol{t} \boldsymbol{a l}$. 1992). As infecções persistentes acarretam diminuição na produção de leite, podendo, ainda, resultar em infecções clínicas (MATTHEWS $\boldsymbol{e t}$ al., 1992). Com base nessas observações, o monitoramento das infecções intramamárias em vacas primíparas, pela contagem de células somáticas e exames microbiológicos, nos primeiros meses de lactação, pode ser útil para a tomada de decisão na adoção de medidas preventivas e terapêuticas.

Considerando a importância das infecções intramamárias, em vacas primíparas e o prejuízo econômico determinado por elas, este trabalho teve por objetivo estudar a etiologia dessas infecções ao longo dos primeiros quatro meses de lactação.

\section{MATERIAL E MÉTODOS}

O trabalho foi realizado em 88 vacas primíparas de quatro rebanhos leiteiros, sendo três localizados na região norte do Estado do Paraná e um no sudoeste do Estado de São Paulo. As propriedades estudadas apresentavam rebanhos compostos por diferentes raças, predominando a holandesa. As quatro propriedades utilizavam ordenha mecânica e adotavam as principais medidas de prevenção e controle, recomendadas para mastite nas vacas em lactação e secas. Para as novilhas, não eram adotadas medidas específicas à prevenção de infecções intramamárias.

O diagnóstico da mastite clínica foi realizado pela observação de sinais de inflamação no úbere, manifestações sistêmicas e a presença de alterações macroscópicas no leite. Para os exames microbiológicos, a colheita das amostras de leite foi precedida de limpeza dos tetos por lavagem, secagem com papel toalha e anti-sepsia com álcool $70^{\circ} \mathrm{GL}$. Cerca de $3 \mathrm{~m} \ell$ de leite foram colhidos em tubos de vidro, com tampa de rosca, e conservado a $-20^{\circ} \mathrm{C}$ até o processamento. As amostras de leite foram obtidas no $1^{\circ}, 7^{\circ}, 14^{\circ}, 28^{\circ}, 60^{\circ}, 90^{\circ}, 120^{\circ}$ dia após o parto. Até o $28^{\circ}$ dia foram obtidas amostras de todos os quartos. Foram considerados isentos de infecção intramamária e, conseqüentemente excluídos do experimento, os animais que apresentaram três culturas bacteriológicas consecutivas negativas, excetuando-se a colheita do $1^{\circ}$ dia após o parto.

Para o isolamento de microrganismos, as amostras de leite foram semeadas em meio de ágarsangue ovino $5 \%$ e incubadas a $37^{\circ} \mathrm{C}$ em aerofilia por um período de até 120 horas. A identificação dos microrganismos foi efetuada segundo as características culturais, morfológicas, tintoriais e bioquímicas (KRIEG \& HOLT, 1984; HARMON et al., 1990). Das 316 culturas de ECN foram selecionadas 49, oriundas de 13 vacas com isolamento positivo em duas ou mais colheitas consecutivas, para posterior identificação pelo sistema API-STAPH (Bio Mérieux, França). Os estreptococos, previamente caracterizados pela prova da catalase, $\mathrm{NaCl} 6,5 \%$, prova de CAMP e esculina, foram classificados em grupos pelo SLIDEX STREPTO-KIT (Bio Mérieux, França). O Corynebacterium bovis (C. bovis) foi identificado pelas provas da catalase, oxidase, oxidação e fermentação, uréia, gelatinase, nitrato, acidificação aeróbica de glicose, maltose, lactose e sacarose (COSTA et al., 1985).

A partir do $14^{\circ}$ dia pós-parto, foi realizada a Contagem de Células Somáticas (CCS), no leite, pelo Laboratório do Programa de Análise de Rebanhos Leiteiros da Associação Paranaense de Criadores de Bovinos da Raça Holandesa (APCBRH). Para a CCS, foram colhidos no início da ordenha da manhã, cerca de $100 \mathrm{~m} \ell$ de leite por quarto e conservados em dicromato de potássio à temperatura ambiente. A contagem foi efetuada eletronicamente por citometria de fluxo (Bentley Somacount 500 - EUA). 


\section{RESULTADOS E DISCUSSÃO}

Das 88 vacas primíparas estudadas nos primeiros 120 dias pós-parto, foram colhidas 1985 amostras de leite, das quais $457 \quad(23,02 \%)$ apresentaram-se positivas nos exames microbiológicos. Em $311(68,05 \%)$ quartos foram isolados ECN em cultura pura, e em $5(1,09 \%)$ em cultura mista, perfazendo um total de $316(69,14 \%)$. O C. bovis foi identificado em $56(12,25 \%)$ quartos. Os estreptococos foram encontrados em cultura pura em $37(8,10 \%)$ quartos e associados a outras bactérias em $4(0,87 \%)$ quartos, totalizando 41 $(8,97 \%)$. Os ECP foram isolados em $37(8,10 \%)$ quartos em cultura pura e, em $1(0,22 \%)$, em cultura mista, somando $38(8,31 \%)$ quartos (Tabela 1). Em estudo realizado na Dinamarca, AARESTRUP \& JENSEN (1997) encontraram, em vacas primíparas, $34 \%$ de amostras de leite positivas, de um total de 1849 examinadas ao longo do $1^{\mathrm{o}}$ mês de lactação.

Neste trabalho, a mastite clínica foi detectada em $9(10,23 \%)$ vacas primíparas. Resultados semelhantes $(11,5 \%)$ foram relatados por DANIEL et al. (1986). Índices mais elevados, 29,0\%, foram registrados por TRINIDAD et $\boldsymbol{a l}$. (1990). PARDO et al. (1998), no Brasil, verificaram sinais de mastite clínica em $20,5 \%$ das vacas primíparas.

Na figura 1, observa-se que o número de animais infectados, no $1^{\circ}$ dia pós-parto, foi de 57 $(64,77 \%)$ com $114(32,66 \%)$ quartos positivos. Esses dados, assim como os de OLIVER (1987), PANKEY et al. (1991) e PARDO et al. (1998) que verificaram respectivamente no $1^{\circ}$ dia pós-parto, $28,1 \%, 18,7 \%$ e $28,9 \%$ de quartos positivos, confirmam os altos índices de infecções intramamárias em vacas primíparas nesse período. Por outro lado, ocorre um decréscimo progressivo no número de infecções nas vacas primíparas e nos

Tabela 1 - Microrganismos isolados de 457 quartos de vacas primíparas ao longo dos primeiros quatro meses de lactação.

\begin{tabular}{lrc}
\hline \multicolumn{1}{c}{ MICRORGANISMOS } & $\mathrm{N}^{\mathrm{o}}$ & $\%$ \\
\hline ECN $^{*}$ & 311 & 68,05 \\
Corynebacterium bovis & 56 & 12,25 \\
Estreptococos & 37 & 8,10 \\
ECP** & 37 & 8,10 \\
Outros & 11 & 2,41 \\
ECN + Estreptococos & 4 & 0,87 \\
ECN + ECP & 1 & 0,22 \\
TOTAL (Quartos Positivos) & 457 & $100 \%$ \\
\hline
\end{tabular}

*ECN - Estafilococos coagulase negativos

**ECP - Estafilococos coagulase positivos quartos até o $14^{\circ}$ dia pós-parto (Figura 1). OLIVER \& MITCHEL (1983), MATTHEWS et al. (1992) e PARDO et al. (1998) também observaram essa diminuição. Provavelmente a frequiência, a higiene e o manejo de ordenha foram responsáveis pela eliminação dos microrganismos nesse período. Neste trabalho, ficou demonstrado que a partir do $14^{\circ}$ dia, o número de infecções intramamárias tendeu a estabilizar nos rebanhos estudados, possivelmente devido à persistência dos microrganismos ou à ocorrência de novas infecções (Figura 1). Neste sentido, o acompanhamento da sanidade da glândula mamária das vacas primíparas apenas nas primeiras semanas pós-parto, pode levar a erros de avaliação.

A figura 2 mostra a freqüência dos principais microrganismos isolados dos primeiros 120 dias pós-parto, ficando evidente a predominância dos ECN ao longo de todo experimento. Em outros trabalhos, em que o período de observação foi menor, os pesquisadores também reportam os ECN como sendo os agentes mais comuns em vacas primíparas (MATTHEWS et al., 1992; MYLLYS, 1995; PARDO et al., 1998; COSTA et al., 1999). Os estreptococos foram isolados com maior freqüência no $1^{\circ}$ dia pós-parto, ocorrendo um decréscimo até o 14º dia. Vários estudos mostram diminuição das infecções intramamárias por Streptococcus dysgalactiae e Streptococcus uberis nas primeiras semanas após o parto (MEANEY, 1981; OLIVER \& MITCHELL, 1983). Em contraposição, AARESTRUP \& JENSEN (1997) verificaram a persistência deles, sugerindo que, tanto o meio ambiente como o animal, podem ser reservatórios de $\boldsymbol{S}$. dysgalactiae. Neste trabalho, houve uma predominância dos estreptococos do grupo C (58,33\%), provavelmente $\boldsymbol{S}$. dysgalactiae e do grupo D $(12,50 \%)$. A presença desses estreptococos, no $1^{\mathrm{o}}$ dia pós-parto e posterior diminuição, pode indicar infecção ambiental no préparto. Ainda na figura 2, observa-se que as infecções por $\boldsymbol{C}$. bovis aumentaram gradativamente ao longo do experimento, talvez devido a eventuais falhas no manejo e higiene da ordenha, principal via de transmissão desse agente. O C. bovis provoca diminuição na secreção láctea e pode ocorrer sob forma de surto além de causar mastite clínica (COSTA et al., 1985 ). Os ECP foram isolados em um número considerado baixo ao longo dos 120 dias, sendo que, ao parto, seis quartos apresentaram infecção, enquanto que no $120^{\circ}$ dia apenas um foi positivo. Esse fato, associado ao não isolamento de S. agalactiae nesta pesquisa, parece indicar que as medidas, adotadas nas propriedades para controle de 


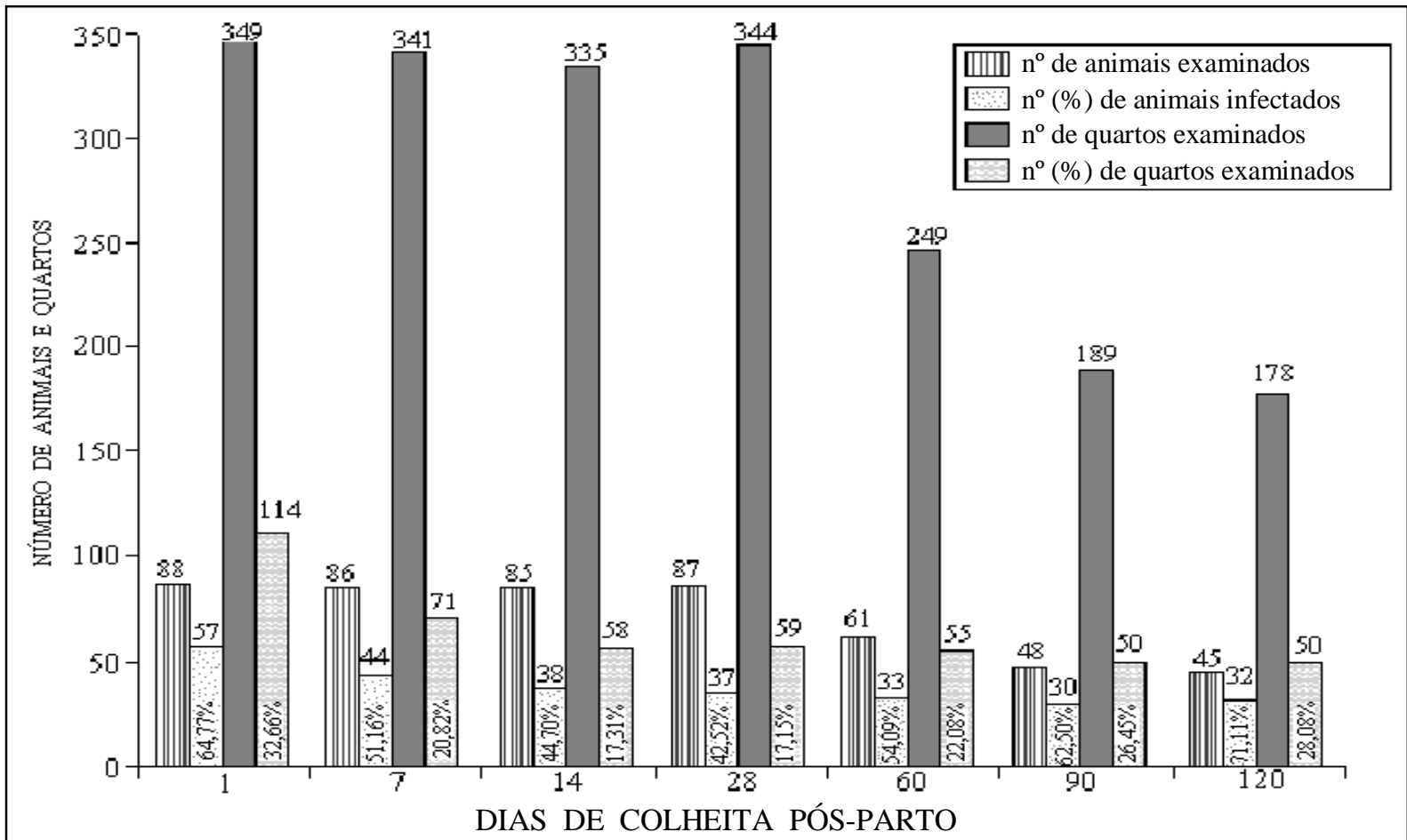

Figura 1 - Número (\%) de vacas primíparas e quartos com infecções intramamárias ao longo dos primeiros 120 dias de lactação.

mastites contagiosas nas vacas em lactação e secas, estavam corretas. Para ROBERSON et al. (1994), pode não haver associação entre a prevalência de infecções por $\boldsymbol{S}$. aureus em novilhas e vacas em lactação. Já para o $S$. agalactiae, a infecção em

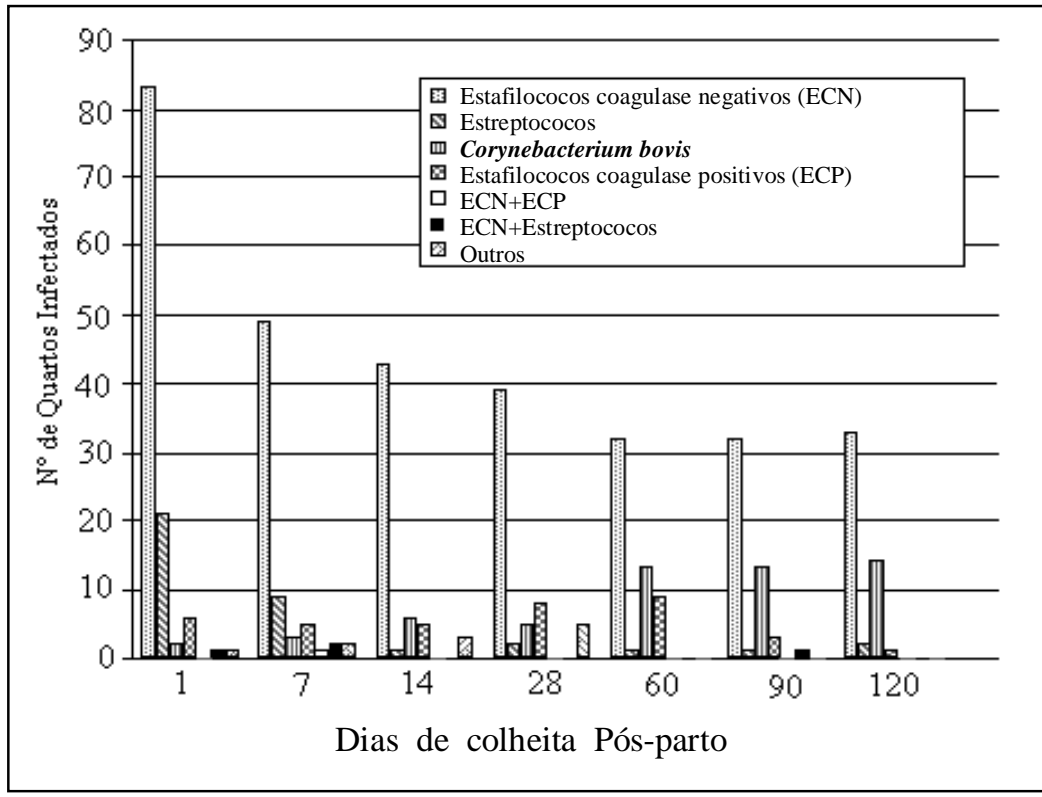

Figura 2 - Distribuição dos microorganismos isolados de 457 quartos de vacas primíparas ao longo dos primeiros 120 dias de lactação. novilhas parece estar associada à ocorrência nas vacas em lactação e manejo das bezerras (SHEARER \& HARMON, 1993).

Especificamente em relação aos ECN, os microrganismos predominantes neste trabalho, procurou-se avaliar o número de quartos com infecções persistentes e novas ao longo dos 120 dias. Observa-se na figura 3 que ocorreu uma queda acentuada nos isolamentos do $1^{\circ}$ dia em relação ao $7^{\circ}$. Em contraposição, a partir deste dia, as infecções persistiram e, ao mesmo tempo, ocorreram novas infecções ao longo de todo experimento. $\mathrm{Na}$ mesma figura, verifica-se ainda que existe uma tendência dos ECN persistirem no úbere, independente do período da infecção. Salienta-se que um certo número de infecções, consideradas como novas neste trabalho, podem ter sido persistentes em função do cultivo de uma amostra de leite por colheita. Das 49 culturas de ECN persitentes nos mesmos quartos, identificadas pelo sistema APISTAPH, $34(69,39 \%)$ foram $\boldsymbol{S}$. hyicus, 8 (16,33\%) S. intermedius,

Ciência Rural, v. 31, n. 6, 2001. 


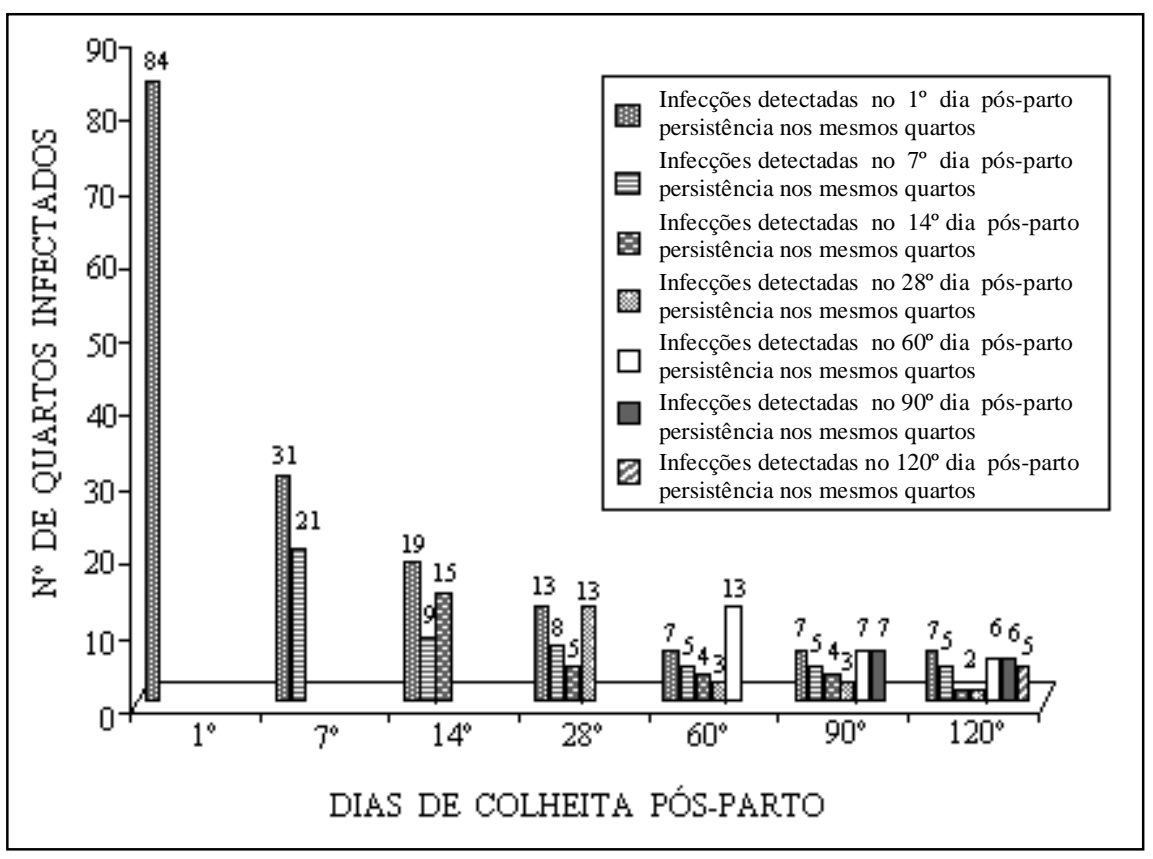

Figura 3 - Número de quartos infectados por estafilococos coagulase negativos (infecções persistentes e novas) em vacas primíparas ao longo dos primeiros 120 dias de lactação. havendo uma tendência de ele desaparecer no início da lactação (AARESTRUP \& JENSEN, 1997).

A média da CCS,
em 905 amostras de
leite bacteriologicamente
negativas, foi de $73.942 / m \ell$
e, em $256 \quad$ amostras
positivas, a contagem foi de
$508.914 / m \ell$. Considerando
a correlação existente entre
infecção, CCS e produção
de leite, pode estimar-se
que as novilhas estudadas
apresentaram uma diminuição
na secreção láctea de 5 a
$10 \%$ na primeira lactação
(HARMON, 1998).

\section{CONCLUSÕES}

Os resultados deste trabalho indicam uma alta ocorrência de infecções $2(4,08 \%)$ S. chromogenes, $2(4,08 \%) \quad S$. haemolyticus, $1(2,04 \%)$ S. simulans e duas não foram identificadas. MYLLYS (1995) descreve a predominância do $\boldsymbol{S}$. hyicus e $\boldsymbol{S}$. simulans em vacas primíparas com mastite clínica no pós-parto, sugerindo que o $\boldsymbol{S}$. hyicus seja a espécie de ECN mais patogênica causando infecção comparável a do S. aureus. WAAGE et al. (1999) também observaram uma acentuada participação do $S$. hyicus em vacas primíparas no pós-parto. Esses dados indicam que, apesar dos $\boldsymbol{S}$. hyicus encontrados neste trabalho terem sido isolados, principalmente de infecções subclínicas, poderão ocorrer casos de mastite clínica. Nos trabalhos de mastite realizados em novilhas, o $\boldsymbol{S}$. intermedius não é citado com freqüência, entretanto, em pesquisa mais recente, CHAFFER et al. (1998), em Israel, detectaram o $\boldsymbol{S}$. intermedius em vacas primíparas, como principal agente entre os ECN. Os resultados deste trabalho mostraram que, entre os ECN isolados, o $S$. intermedius foi o segundo mais freqüente. Novos estudos devem ser realizados para verificar as possíveis fontes de infecção para novilhas.

Das amostras de ECN pesquisadas no API- STAPH, apenas duas foram identificadas como S. chromogenes, apesar de ser descrito como um dos mais freqüentes em novilhas (MATTHEWS et al., 1992; MYLLYS, 1995). Essas descrições referem-se ao isolamento do $S$. chromogenes em novilhas no pré-parto e imediatamente após o parto, intramamárias nas vacas primíparas, com predominância dos estafilococos coagulase negativos (ECN). As infecções por ECN e estreptococos decresceram ao longo das primeiras semanas pós-parto, ao contrário, as infecções por $\boldsymbol{C}$. bovis aumentaram gradativamente a partir do parto. O leite dos quartos mamários infectados apresentou contagem de células somáticas (CCS) superiores às dos quartos não infectados. Esses dados justificam a adoção de medidas preventivas e de controle especiais para as novilhas no pré e pós-parto, constituindo-se o acompanhamento pela CCS e exames microbiológicos em importantes ferramentas para o monitoramento da saúde da glândula mamária.

\section{REFERÊNCIAS BIBLIOGRÁRFICA}

AARESTRUP, F.M., JENSEN, N.E. Prevalence and duration of intramammary infection in Danish heifers during the peripartum period. J Dairy Sci, v.80, p.307-312, 1997.

CHAFFER, M., LEITNER, G., WINKLER, M., et al. Coagulasenegative Staphylococcus intermedius isolated from milk from dairy cows in Israel. Vet Rec, v.21, n.143, p.592-593, 1998.

COSTA, E.O, CARVALHO, V.M., COUTINHO, S.D., et al. Corynebacterium bovis e sua importância na etiologia bovina no Estado de São Paulo. Pesq Vet Bras, v.5, n.4, p.117-120, 1985.

COSTA, E.O., MELVILle, PA, RIBEIRO, A.R., $\boldsymbol{e t}$ al. Prevalence of intramammary infections in primigravid 
Brazilian dairy heifers. Prev Vet Med, v.29, p..151155,1996

COSTA, E.O., MELVILlE, P.A., RIBEIRO, A.R., $\boldsymbol{e}$ t al. Infecções intramamárias em novilhas primíparas no período pré ao pós-parto e sua importância no controle de mastite. Napgama, n.1, p.16-20, 1999.

DANIEL, R.C.W., BARNUM, D.A., LESLIE, K.E. Observations on intramammary infections in first calf heifers in early lactation. Can Vet J, v.27, p.112-115, 1986.

FOX, L.K., CHESTER, S.T., HALLBERG, J.W., et al. Survey of intramammary infections in dairy heifers at breeding age and first Parturition. J Dairy Sci, v.78,p.1619-1628,1995.

HALlBERG, J.W., DAME, K.J., CHESTER, S.T., et al. The visual appearance and somatic cell count of mammary secretions collected from primigravid heifers during gestation and early postpartum. J Dairy Sci, v.78, p.1629-1636, 1995.

HARMON, R.J. Fatores que afetam as contagens de células somáticas. In: SIMPÓSIO INTERNACIONAL SOBRE QUALIDADE DO LEITE, 1, 1998. Curitiba. Anais... Curitiba : APCBRH, 1998. p.7-15.

HARMON, R.J., EBERHART, R.J., JASPER, D.E., $\boldsymbol{e}$ t al Microbiological procedures for diagnosis of bovine udder infection. Arlington : Nat Mastitis Counc, 1990.

KRIEG, N.R, HOLT, J.G. Bergey's manual of systematic bacteriology. 9.ed. Baltimore : Williams \& Wilkins, 1984. $1268 \mathrm{p}$.

MATTHEWS, K.R., HARMON, R.J., LANGLOIS, B.R. Prevalence of Staphylococcus species during the periparturient period in primiparous and multiparous cows. J Dairy Sci, v.75, p.1835-1839, 1992.

MEANEY, W.J. Mastitis levels in spring-calving dairy heifers. Irish Vet J, v.35, p.205-209,1981.

MYLLYS, V. Staphylococci in heifer mastitis before and after parturition. J Dairy Res, v.62, p.51-60, 1995.
MUNCH-PETERSEN, E. Mastitis in bovine primiparae. Vet Rec, v.87, p.568-574, 1970 .

OLIVER, S.P., MITCHELL, B.A. Intramammary infections in primigravid heifers near parturition. J Dairy Sci, v.66, p.1180-1183, 1983

OLIVER, S.P. Intramammary infections in heifers at parturiation and during early lactation in a herd with high prevalence of environmental mastitis. Tennessee Farm and Home Sci, v.143, p.18-22, 1987.

PANKEY, J.W., DRECHSLER, P.A., WILDMAN, E.E. Mastitis prevalence in primigravid heifers at parturition. J Dairy Sci, v.74, n.5, p.1550-1553, 1991.

PARDO, P.E., METTIFOGO, E., MULLER, E.E., et al. Etiologia das infecções intramamárias em vacas primíparas no período pós-parto. Pesq Vet Bras, v.18, n.3-4, p.115-118, 1998.

ROBERSON, J.R., FOX, L.K., HANCOCK, D.D., et al. Ecology of Staphylococcus aureus isolated from various sites on dairy farms. J Dairy Sci, v.77, n.11, p.3354-3364, 1994.

SHEARER, J.K., HARMON, R.J. Mastitis in heifers. Vet Clin North Am: Food Anim Pract, v.9, p.583-595, 1993.

STABELFORTH, A.W., EDWARDS, S.J., MINETT, F.C Studies on bovine mastitis. J Comp Path Ther, v.48, p.300315, 1935.

TRINIDAD, P., NICKERSON, S.C., ALLEY, T.K. Prevalence of intramammary infection and teat canal colonization in unbred and primigravid dairy heifers. J Dairy Sci, v.73, p.107-112, 1990 .

WAAGE, S., MØRK, T., RØROS, A., et al. Bacteria associated with clinical mastitis in dairy heifers. J Dairy Sci, v.82, p.712-719, 1999.

Ciência Rural, v. 31, n. 6, 2001. 